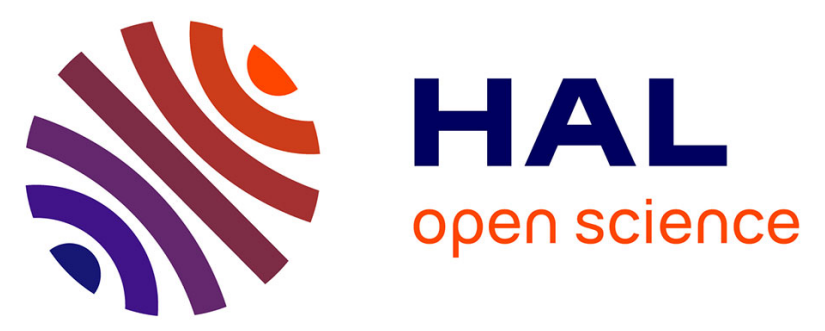

\title{
Pru p 7 sensitization is a predominant cause of severe, cypress pollen-associated peach allergy
}

Caroline Klingebiel, Yannick Chantran, Rihane Arif-lusson, Angelica

Ehrenberg, Jonas Östling, Alain Poisson, Valérie Liabeuf, Chantal Agabriel, Joëlle Birnbaum, Françoise Porri, et al.

\section{To cite this version:}

Caroline Klingebiel, Yannick Chantran, Rihane Arif-lusson, Angelica Ehrenberg, Jonas Östling, et al. Pru p 7 sensitization is a predominant cause of severe, cypress pollen-associated peach allergy. Clinical and Experimental Allergy, 2019, 49 (4), pp.526-536. 10.1111/cea.13345 . hal-02202464

\section{HAL Id: hal-02202464 \\ https://hal-amu.archives-ouvertes.fr/hal-02202464}

Submitted on 14 Oct 2019

HAL is a multi-disciplinary open access archive for the deposit and dissemination of scientific research documents, whether they are published or not. The documents may come from teaching and research institutions in France or abroad, or from public or private research centers.
L'archive ouverte pluridisciplinaire HAL, est destinée au dépôt et à la diffusion de documents scientifiques de niveau recherche, publiés ou non, émanant des établissements d'enseignement et de recherche français ou étrangers, des laboratoires publics ou privés. 


\title{
Pru p 7 sensitization is a predominant cause of severe, cypress pollen-associated peach allergy
}

\author{
Caroline Klingebiel $^{1}$ | Yannick Chantran ${ }^{2,3}$ | Rihane Arif-Lusson ${ }^{4}$ | Angelica E. Ehrenberg ${ }^{5}$ | \\ Jonas Östling $^{5}$ | Alain Poisson ${ }^{6}$ | Valérie Liabeuf ${ }^{7}$ | Chantal Agabriel ${ }^{8}$ | \\ Joëlle Birnbaum ${ }^{9}$ | Françoise Porri ${ }^{6}$ | Anne Sarrat ${ }^{10}$ | Pol-André Apoil ${ }^{11}$ | \\ Mylène Vivinus $^{12}$ | Lorna Garnier ${ }^{13}$ | Anca Mirela Chiriac ${ }^{14,15}$ | Davide-Paolo Caimmi ${ }^{14,15}$ | \\ Jean-Luc Bourrain ${ }^{14}$ | Pascal Demoly ${ }^{14,15}$ | Stéphane Guez ${ }^{16}$ | Franck Boralevi ${ }^{17}$ | \\ Bertrand Lovato $^{18}$ | Céline Palussière ${ }^{19}$ | Sylvie Leroy ${ }^{20}$ | Thierry Bourrier ${ }^{21}$ | \\ Lisa Giovannini-Chami ${ }^{21}$ | Marion Gouitaa ${ }^{22}$ | Agnès Aferiat-Derome ${ }^{23}$ | Denis Charpin ${ }^{24}$ | \\ Tünde Sofalvi $^{22}$ | Isabelle Cabon-Boudard ${ }^{25}$ | Yann-Patrick Massabie-Bouchat ${ }^{26}$ | \\ Bernard Hofmann $^{27}$ | Nathalie Bonardel ${ }^{28}$ | Mireille Dron-Gonzalvez ${ }^{29}$ | \\ Benoît Sterling $^{30,31}$ | Ania Carsin ${ }^{31, \dagger}$ | Serge Vivinus ${ }^{20}$ | Bernard Poitevin ${ }^{32}$ | \\ Laureline Nicolau $^{33}$ | Geneviève Liautard ${ }^{34}$ | Christophe Soler ${ }^{1}$ | Soraya Mezouar ${ }^{4}$ |
}

Isabella Annesi-Maesano ${ }^{15}$ | Jean-Louis Mège ${ }^{4}$ | Jonas Lidholm ${ }^{5}$ | Joana Vitte ${ }^{4}$ and the ANAFORCAL and AllergoBioNet Networks

\footnotetext{
${ }^{1}$ Laboratoire Synlab Provence, Marseille, France

2UPMC Univ Paris 06, INSERM UMRS 938, Centre de Recherche Saint-Antoine, team "Immune System, Neuroinflammation and Neurodegenerative Diseases",

Hôpital Saint-Antoine, Sorbonne Universités, Paris, France

${ }^{3}$ Immunology Department, AP-HP Saint-Antoine Hospital, Paris, France

${ }^{4}$ Aix-Marseille Univ, IRD, APHM, MEPHI, IHU Méditerranée Infection, Marseille, France

${ }^{5}$ Thermo Fisher Scientific, Uppsala, Sweden

${ }^{6}$ Service de Pneumo-Allergologie, Hôpital Saint Joseph, Marseille, France

${ }^{7}$ Aix-Marseille Univ, APHM, Hôpital Timone, Service de Dermatologie-Vénéréologie, Marseille, France

${ }^{8}$ Aix-Marseille Univ, APHM, Hôpital Timone, Service de Pédiatrie Multidisciplinaire, Marseille, France

${ }^{9}$ Service de Pneumologie et Allergologie, $\mathrm{CH}$ du Pays d'Aix, Aix-en-Provence, France

${ }^{10}$ Laboratoire d'Immunologie et Immunogénétique, GH Pellegrin, CHU Bordeaux, Bordeaux, France

${ }^{11}$ Institut Fédératif de Biologie, Hôpital Purpan, CHU Toulouse, Toulouse, France

${ }^{12}$ Laboratoire d'Immunologie, Hôpital de l'Archet, CHU Nice, Nice, France

${ }^{13}$ Laboratoire d'Immunologie, $\mathrm{CH}$ Lyon Sud, CHU Lyon, Pierre-Bénite, France

${ }^{14}$ Département de pneumologie et addictologie, CHU Montpellier, Hôpital Arnaud-de-Villeneuve, Univ Montpellier, Montpellier, France

${ }^{15}$ Sorbonne Universités, INSERM UMRS 1136, IPLESP, team EPAR, Paris, France

${ }^{16}$ Unité d'allergologie, GH Pellegrin, CHU Bordeaux, Bordeaux, France

${ }^{17}$ Unité de Dermatologie Pédiatrique, Hôpital Pellegrin-Enfants, CHU Bordeaux, Bordeaux, France

${ }^{18}$ Medical Office, Mérignac, France

${ }^{19}$ Medical Office, Cenon, France

${ }^{20}$ Service de Pneumologie, Hôpital Pasteur, CHU Nice, Nice, France

${ }^{21}$ Hôpitaux Pédiatriques de Nice, $\mathrm{CHU}$ Lenval, Nice, France

${ }^{22}$ Aix-Marseille Univ, APHM, Hôpital Nord, Service de Pneumologie, Marseille, France

${ }^{23}$ Medical Office, Les Jardins de Castellane, Marseille, France

${ }^{24}$ Aix-Marseille Univ, APHM, Hôpital Timone, Unité de Pneumologie, Marseille, France

${ }^{25}$ Aix-Marseille Univ, APHM, Hôpital Timone, Service de Chirurgie Pédiatrique, Marseille, France
} 


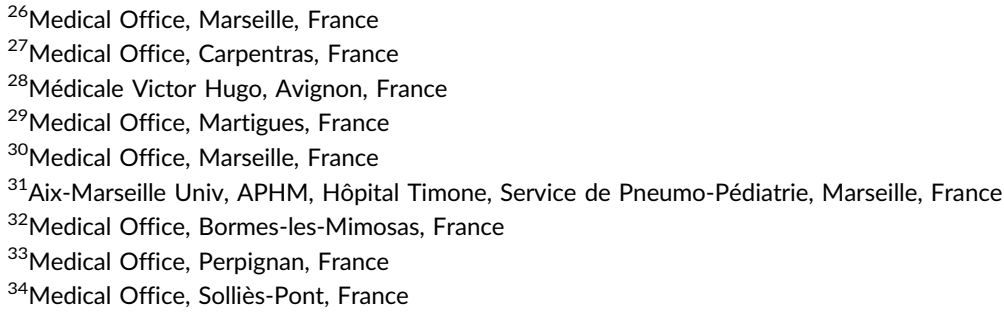

\section{Correspondence}

Joana Vitte, IHU Méditerranée Infection,

Marseille, France.

Email: jvitte@ap-hm.fr

\section{Present address}

Ania Carsin, Department of Pediatrics, Hôpital Saint Joseph, Marseille, France.

\section{Funding information}

This work was supported by the French Society of Allergology (Société Française d'Allergologie) 2017 through a research grant (JV)

\begin{abstract}
Background: Peach is a common elicitor of food allergic reactions. Peach-induced immediate reactions may occur as benign pollen-food syndromes, usually due to birch pollen-related PR-10 cross-reactivity in temperate climates, and as potentially severe primary food allergies, predominantly related to nsLTP Pru $p 3$ in Mediterranean regions. The newly described peach allergen Pru $\mathrm{p} 7$ has gained recent attention as a potential peach allergy severity marker. Sensitization to Pru p 7 and its allergenic homologues of the gibberellin-regulated protein family occurs in areas with high Cupressaceae tree pollen exposure.
\end{abstract}

Objective: We sought to investigate the distribution, clinical characteristics and molecular associations of Pru p 7 sensitization among subjects with suspected peach allergy in different regions of France.

Methods: Subjects with suspected peach allergy $(n=316)$ were included. Diagnostic work-up was performed according to current guidelines, including open food challenge when required. IgE antibody measurements and competition experiments were performed using the ImmunoCAP assay platform.

Results: Sensitization to Pru p 7 was present in 171 (54\%) of all subjects in the study and in 123 of 198 (62\%) diagnosed as peach allergic, more than half of whom were sensitized to no other peach allergen. Frequency and magnitude of Pru $p 7$ sensitization were associated with the presence of peach allergy, the clinical severity of peach-induced allergic reactions and the level of cypress pollen exposure. Cypress pollen extract completely outcompeted IgE binding to Pru p 7. Pru p 7 was extremely potent in basophil activation tests.

Conclusion and Clinical Relevance: A subtype of Cupressaceae pollinosis, characterized by Pru $\mathrm{p} 7$ sensitization, can be an underlying cause of severe peach allergy.

\section{KEYWORDS}

allergens and epitopes, anaphylaxis, basophil, cypress pollinosis, food allergy, IgE, immunological tests, peamaclein, Pru p 7

\section{1 | INTRODUCTION}

Fruit and vegetables account for the most common aetiology of food allergies in teenagers and adults. ${ }^{1-4}$ Severe reactions are frequent, with fruit and vegetables reported as causative in $5 \%$ of all cases of food anaphylaxis in children and adolescents in a range of European countries, ${ }^{5}$ and confirmed as culprit in $7 \%$ of children seeking emergency care at a major Madrid hospital for anaphylaxis-like symptoms. ${ }^{6}$ Peach-induced immediate reactions are frequent in pollen-allergic patients and often occur as pollen-food syndromes (PFS). ${ }^{7-9}$ Birch pollen-related PR-10 sensitization underlies most cases of peach-induced oral allergy syndrome (OAS) occurring in temperate climates, while sensitization to non-specific lipid transfer proteins (nsLTPs) is predominant in Mediterranean regions and may induce OAS as well as severe reactions. ${ }^{1,4,9-11}$ In southern Europe, primary food allergies, including peach allergy (PA), may account for 
up to $96 \%$ of food allergy cases. ${ }^{1}$ Sensitization to nsLTPs, either as primary food allergy or as PFS, accounts for most of PA cases in the Mediterranean region. ${ }^{1,12,13}$ However, some PA patients have been found to lack sensitization to Pru p 1 (PR-10), Pru p 3 (nsLTP) and Pru p 4 (profilin), despite a convincing clinical history and a strongly positive skin test with fresh peach. ${ }^{14-16}$ Pru $p ~ 7$, also referred to as peamaclein, a member of the gibberellin-regulated protein (GRP) family, was described as a novel peach allergen. ${ }^{14}$ We have previously reported Pru p 7 as a major allergen associated with severe clinical symptoms and strong cypress pollen (CP) sensitization in PA patients from Marseille, southern France. ${ }^{16}$ As France comprises a wide spectrum of geographic and climatic conditions, including continental, oceanic, Mediterranean and alpine regions, a variety of pollen sensitizations may occur across the country, making a fuller understanding of different pollen-related food allergies particularly relevant. In this study, we set out to further characterize the implications of Pru p 7 sensitization in PA in Mediterranean and non-Mediterranean regions of France.

\section{2 | METHODS}

\section{1 | Patients}

Three hundred sixteen outpatients residing in southern France (42nd to 46th latitude north), seeking allergy work-up for a suspicion of peachinduced food allergy symptoms, were included in this study. Clinical data were collected by means of a standardized questionnaire retrospectively completed by the allergists. Continental, oceanic and Mediterranean climates were represented. Five geographic regions were defined based on cypress and birch pollen counts ${ }^{17}$ and numbered 1-5 according to ascending order of cypress/birch pollen count ratio: region 1 (Lyon and continental environments), region 2 (Bordeaux and neighbouring Atlantic coastal regions), region 3 (alpine and continental regions including Toulouse and southern Alps), region 4 (Nice and Montpellier regions) and region 5 (Marseille and Var regions, southernmost Mediterranean environments) (Table 1). Each participant's area of residency was categorized as belonging to one of these regions.

\section{2 | Diagnostic criteria and procedures}

Diagnosis of PA was confirmed or rejected according to ICON and EAACl guidelines for food allergy. ${ }^{18-20}$ The combination of a convincing clinical history of immediate reaction to peach in the past year, positive skin prick tests (SPT) to peach extract (Stallergènes-Greer, ALK-Abelló) or fresh peach defined as a weal $>50 \%$ of the positive control, and/or IgE sensitization to peach, formed the basis of a PA diagnosis. ${ }^{20}$ Convincing clinical history was defined as one or more immediate reaction (s) within 2 hours after peach ingestion, inhalation or direct contact, presenting as acute urticaria or angioedema, contact urticaria, OAS, food-dependent exercise-induced anaphylaxis, laryngeal swelling, immediate vomiting, rhinitis, cough, wheezing, bronchospasm, hypotension or loss of consciousness. The use of peach-specific lgE determination in conjunction with clinical history and peach SPT helped reduce the need for oral food challenge (OFC) as advised. ${ }^{21}$ Diagnostic OFC was performed according to ICON and EAACl guidelines ${ }^{18,20}$ and previous PA studies ${ }^{3,11}$ if negative SPT and IgE results were discordant with clinical history. Patients who had had a life-threatening reaction to peach during the last 12 months did not undergo OFC, in line with current guidelines. ${ }^{18} \mathrm{~A}$ total of 61 patients were subjected to OFC, of whom 41 failed (PA) and 20 passed (peach tolerant, PT).

OFC followed an open protocol, with peach peel and pulp tested separately. After a negative labial challenge test, doses of fresh peach were administered in sequential 20-minute steps, starting the provocation with $1 / 128$ of one fruit (approximately $1 \mathrm{~g}$ ), then proceeding with $1 / 64,1 / 32,1 / 16,1 / 8,1 / 4$ and $1 / 2$ (highest dose approximately $65 \mathrm{~g}$ ). The OFC was stopped if objective or severe symptoms appeared: erythema, urticaria, sneezing, wheezing, cough, vomiting, severe abdominal pain, hypotension, neurological symptoms or difficulty to breathe. Patients were kept in day-care units at close proximity of an intensive care unit during the challenge procedure and were monitored for 4 hours after ingestion of the last dose of peach. At the end of the diagnostic procedure, patients were categorized as PA or PT.

The diagnostic investigation for other food allergies followed the same steps as that for PA.

\subsection{Assessment of clinical severity}

The severity of clinical reactions was graded following the recently proposed classification of food allergic and anaphylactic reactions $^{22,23}$ : grade 1 comprising local reactions without systemic involvement: redness, swelling and itching; grade 2 mild to moderate systemic reactions involving distant skin locations, upper airways and/or gastrointestinal symptoms, but without cardiovascular or respiratory involvement: urticaria, angioedema, flush and gastrointestinal symptoms; grade 3 severe systemic reactions with cardiovascular and/or bronchial and laryngeal involvement: wheezing, stridor, objective dyspnoea, tachycardia, lowered blood pressure and shock.

\subsection{Ethics statement}

Determination of IgE to whole allergen extracts and molecular allergens was part of routine investigations. Patients received written laboratory reports and the study was based on a retrospective review of medical records and laboratory results. In accordance with the Declaration of Helsinki and the French law on research involving humans, ethics committee approval and patient consent were not required for this type of non-interventional study, provided the patients received information and retained the right to oppose to the use of excess serum and anonymized medical data for research purposes. ${ }^{24,25}$

\section{5 | IgE antibody measurements}

IgE antibodies directed to natural extracts and molecular allergens were measured with the ImmunoCAP ${ }^{\mathrm{TM}}$ assay platform (Thermo Fisher Scientific, Uppsala, Sweden) during the routine diagnostic procedure. 
All sera were assayed for IgE to peach, CP, PR-10 protein rPru $\mathrm{p} 1$, nsLTP rPru $p 3$, profilin rPru $\mathrm{p} 4$, the major and specific CP allergen pectate lyase nCup a 1 , and MUXF3, representing cross-reactive carbohydrate determinants (CCD). IgE assays to additional allergen extracts and components were performed according to each patient's history. IgE to natural and recombinant Pru $\mathrm{p} 7$ was measured on excess serum with experimental ImmunoCAP ${ }^{\mathrm{TM}}$ tests. rPru $\mathrm{p} 1$ and $\mathrm{rPru}$ p 4 were taken as surrogates for their respective allergen families due to high level of molecular similarity and cross-reactivity. ${ }^{2,26}$ Pru $\mathrm{p} 3$, the immunodominant nsLTP and a possible primary sensitizer for this allergen family, ${ }^{12,27}$ was considered representative of nsLTP sensitization. Specific IgE values exceeding the assay's stated limit of quantitation of $0.10 \mathrm{kU}_{\mathrm{A}} / \mathrm{L}$ were considered positive. ${ }^{28}$ For comparison of the experimental ImmunoCAP assay to an independent method for detection of IgE to $\mathrm{nPru} p \mathrm{p}$, a subset of sera were analysed with the multiplexed FABER ${ }^{\circledR}$ assay (CAAM, Rome, Italy). ${ }^{29,30}$

\subsection{Preparation of natural and recombinant peach allergens and experimental ImmunoCAP ${ }^{\mathrm{TM}}$ tests}

Natural Pru p 7 was purified from extract of canned peaches by sequential steps of cation exchange, size exclusion and reversed phase chromatography. Bioaffinity adsorption was then performed to eliminate any residual amount of LTPs. Natural Pru p 3 was purified from peach peel extract by affinity chromatography using a monoclonal anti-Pru p 3 antibody, followed by cation exchange chromatography. Recombinant Pru p 7 and Pru p 3 were expressed in Pichia pastoris and purified from culture medium by cation exchange or metal ion affinity chromatography, followed by size exclusion or cation exchange chromatography. Purity, homogeneity and identity of the allergen preparations were verified by SDS-PAGE, analytical size exclusion chromatography, mass spectrometry and immunological activity using ImmunoCAP ${ }^{\mathrm{TM}}$ and serum samples with defined IgE reactivities. All chromatography media and equipment were obtained from GE Healthcare Life Sciences (Uppsala, Sweden). Experimental ImmunoCAP ${ }^{\mathrm{TM}}$ tests were prepared as described. ${ }^{31}$

\section{7 | IgE competition experiments}

Cross-reactivity between Pru p 7 and CP was studied by preincubating serum samples for 2 hours at room temperature either with $C P$ extract (15\% w/v final concentration, 42 sera) or with rPru $p 7$ (100 $\mu \mathrm{g} / \mathrm{mL}$ final concentration, 33 sera) prior to measurement of IgE binding to rPru p 7 or CP ImmunoCAP solid phase, respectively. Percent inhibition was calculated as reduction of lgE binding in comparison with serum samples pre-incubated with buffer alone. Dose-dependent inhibition was performed with four samples. Two samples were incubated with $15 \%(w / v) C P$ extract and a 4-fold dilution series thereof, followed by measurement of IgE binding to Pru $p$ 7. Two other samples were instead pre-incubated with rPru $p 7$ in a 4-fold dilution series from 200 to $0.2 \mu \mathrm{g} / \mathrm{mL}$, followed by measurement of IgE binding to $\mathrm{CP}$ extract.

\section{8 | Basophil activation tests}

Basophil activation tests (BAT) were performed with a commercial CD193 (CCR3)/CD63 kit (Bühlmann Laboratories, Hochbuch, Switzerland) in a subset of patients. Peach extract, Mal d 1 (PR-10), Tri a 12 (profilin), and cow's milk extract (Bühlmann Laboratories) and recombinant and natural Pru p 7 and Pru p 3 were used as allergen reagents. Milk extract served as a negative control for foods regularly consumed and tolerated by each tested patient. Extracts

TABLE 1 Geographic and demographic characteristics of the study population

\begin{tabular}{|c|c|c|c|c|c|c|}
\hline & All regions & Region 5 & Region 4 & Region 3 & Region 2 & Region 1 \\
\hline \multicolumn{7}{|c|}{ Pollen counts (per year and m3) } \\
\hline Birch & 639 & 69 & 176 & 226 & 1077 & 1648 \\
\hline Cypress/birch ratio & 18 & 272 & 98 & 19 & 8 & 5 \\
\hline All patients & 316 & 205 & 27 & 35 & 28 & 21 \\
\hline \multicolumn{7}{|l|}{ Peach allergic patients } \\
\hline Sample size (number, \%) & $198(63 \%)$ & $133(65 \%)$ & $22(81 \%)$ & $20(57 \%)$ & $13(46 \%)$ & $10(48 \%)$ \\
\hline Sex ratio (M/F) & 0.8 & 0.8 & 1.0 & 0.5 & 1.2 & 0.8 \\
\hline Age (years; median, IQR) & $21(13-36)$ & $21(13-36)$ & $32(21-47)$ & $19(14-32)$ & $17(9-31)$ & $16(13-34)$ \\
\hline Age (years; median, IQR) & $15(10-28)$ & $14(9-26)$ & $15(13-24)$ & $23(10-32)$ & $15(10-25)$ & $17(10-31)$ \\
\hline
\end{tabular}

Regions 1-5 were defined in ascending order of cypress to birch ratio. Outpatients seeking allergy work-up for a history of peach-induced symptoms were included. Peach allergy was confirmed or rejected according to ICON and EAACI guidelines for food allergy. 
and molecular allergens obtained from Bühlmann Laboratories were used at final concentrations of 2.5, 1, 0.5 and 0.05 times the manufacturer's recommended concentration, that is $62.5,25,12.5$ and $1.25 \mathrm{ng} / \mathrm{mL}$ for peach and milk extracts, and 625, 250, 125 and $12.5 \mathrm{ng} / \mathrm{mL}$ for Mal d 1 and Tri a 12.

Natural and recombinant Pru p 7 was applied at 11 different concentrations, ranging from $0.25 \mathrm{pg} / \mathrm{mL}$ to $2.5 \mu \mathrm{g} / \mathrm{mL}$. Natural and recombinant Pru p 3 was applied at final concentrations of $5 \mathrm{ng} /$ $\mathrm{mL}, 50 \mathrm{ng} / \mathrm{mL}$ and $2.5 \mu \mathrm{g} / \mathrm{mL}$. Positive and negative controls (patient background, anti-FceRI and formyl-methionyl-leucyl-phenylalanine) were assayed in duplicate at the start and end of the experiment for each patient. Analysis was performed with a Canto II flow cytometer and FACS Diva software (BD Biosciences, Franklin Lakes, $\mathrm{NJ})$. Five hundred basophils or more were analysed for each activation condition. Background CD63 expression was lower than 5\% in all patients, and no non-responder (anti-FceRI-induced CD63 expression of $10 \%$ or less) was found. BAT was considered positive for an allergen concentration if CD63 expression exceeded twice the highest background result in each patient. $\mathrm{EC}_{50}, \mathrm{CD}$-sens and the ratio of maximal activation Pru $\mathrm{p} 7 /$ anti-Fc\&RI activation were calculated as described. ${ }^{32,33}$

\section{9 | Statistical data analysis}

Median and IQR for IgE were calculated for sensitized subjects in each group. GraphPad Prism (version 7, La Jolla, CA), SPSS (version 25, Chicago, IL) and R (version 3.3.2, R Foundation for Statistical Computing, Vienna, Austria) were used for statistical analyses. Differences with a $P$ value $<0.05$ were considered statistically significant. Binomial variables were compared using Fisher's exact test and modelled according to multiple binomial logistic regression models. Ordinal variables (reaction grade and region of residency according to pollen counts) were compared using the asymptotic general independence test and modelled according to multiple ordinal regression models. Continuous variables were compared using Mann-Whitney's test and modelled according to multiple linear regression models. Correlation studies were done by calculating Spearman's correlation coefficient. Odds ratios were calculated as previously described. ${ }^{34}$

\section{3 | RESULTS}

\subsection{Demographic and food allergy characteristics of the study population}

A total of 316 patients from the southern part of France were retrospectively included in the study, with a median age of 18 years (range 0.13-74) and sex (M/F) ratio 0.7. Subjects were classified according to two diagnostic categories: PA and PT (Table 1). PA was diagnosed in 198 (63\%) patients. Allergy to other fruits (mainly Rosaceae, Citrus and exotic fruits) was found in 157 (79\%) of PA patients, while allergy to legumes, tree nuts, cereals and seeds was found in 46 (23\%). Among the 118 PT patients, allergy to other fruits or vegetables was found in $42(36 \%)$ and to legumes, tree nuts, cereals and seeds in 64 (54\%). In 33 (28\%) of the PT subjects, no plant food allergy was found (Figure S1). Involvement of a cofactor was reported in 24 (12\%) of the PA patients, exercise being the most frequent $(n=19)$. Among the symptoms experienced, eyelid oedema was reported by $19(10 \%)$ of the PA patients.

\subsection{Pru p 7 sensitization is present in all regions and is higher and more common in PA than PT patients}

Overall, Pru p 7 sensitization was found in 171/316 (54\%) patients (Table 2). A gradient of Pru p 7 sensitization from north (region 1, $29 \%$ prevalence) to south (region 5, 60\% prevalence) was observed, $\mathrm{P}=0.003$ (Figure 1). Pru p 7 sensitization was more frequent in PA $(123 / 198,62 \%)$ than in PT $(48 / 118,41 \%)$ patients, $P=0.0002$. It was positively and independently related to PA (OR [C195]: 2.5 [1.44.6]; $P=0.003$ ). Apparent monosensitization to Pru $p 7$, that is without detectable IgE to any of the other tested peach allergens (Pru $p$ 1, Pru p 3, Pru p 4), was more frequent in PA $(66 / 123,54 \%)$ than in PT $(8 / 48,17 \%)$ patients, $P<0.0001$.

The concentrations of IgE to Pru p 7 were higher in PA than PT patients sensitized to this allergen (median [IQR]: 3.4 [0.5-8.3] vs 0.3 [0.2-0.5] kU $\mathrm{kU}_{\mathrm{A}} / \mathrm{L} ; P<0.0001$ ) (Table 2). Data on sensitization to other molecular allergens in PA and PT patients are available in Tables S1 and S2.

For comparative purposes, sera of six PA subjects with IgE to Pru p 7 by ImmunoCAP were also analysed with the FABER ${ }^{\circledR}$ assay (CAAM, Rome, Italy) and concordant results were obtained in five of these (83\%).

\subsection{Pru p 7 sensitization is associated with the severity of reaction and cofactor involvement}

Figure 2 shows the levels of IgE antibody responses to peach, individual peach components, $C C D$ and $C P$ in the PA and PT subjects, illustrating the prominent difference in Pru $\mathrm{p} 7$ sensitization between these groups. Further, Pru p 7 sensitization was more frequent in PA patients who experienced grade 3 reactions $(61 / 78,78 \%)$ than in those who experienced grade $2(38 / 59,64 \%)$ or grade 1 (24/61, $39 \%$ ) reactions, $P<0.0001$ (Figure $3 \mathrm{~A}$ ). Likewise, the severity of reactions elicited by peach was significantly associated with the concentration of IgE to Pru $\mathrm{p} 7$ (Figure 3B). Odds ratio calculation showed that Pru p 7 sensitization was positively and independently related to a higher prevalence of grade 3 reactions (OR [CI95]: 3.7 [1.6-8.5]; $P=0.002$ ), and negatively related to grade 1 (OR [Cl95]: 0.2 [0.1-0.4]; $P<0.0001$ ). This association remained significant after adjustment for sensitization to other peach allergens and to $\mathrm{CP}$ as potential confounding covariates.

Cofactor involvement was significantly more frequent in Pru p 7 sensitized patients (22/171 vs $7 / 145, P=0.01)$, but eyelid oedema during the allergic reaction was not $(15 / 171$ vs $5 / 145, P=0.06)$. 


\subsection{Pru p 7 induces basophil activation in PA patients}

The ability of Pru p 7 to activate effector cells was assessed with BAT (Figure 4). The test was performed with peach extract, natural and recombinant Pru p 7, available representative molecules for relevant allergen families: nsLTP (Pru p 3), PR-10 (Mal d 1) and profilin (Tri a 12), and a tolerance control allergen, that is cow's milk, in 9 PA patients sensitized to Pru p 7 and in one PT, Pru p 7 non-sensitized patient with plant food-induced anaphylaxis. Comparable results were obtained with the natural and recombinant Pru p 7 and with natural and recombinant Pru $\mathrm{p} 3$. All Pru p 7-sensitized patients displayed basophil activation induced by peach extract and Pru $\mathrm{p} 7$ as monitored by CD63 membrane expression, but no activation with the other allergens tested, nor with cow's milk extract (Table S3). The PT patient's basophils were not activated by any of the extracts or molecular allergens tested (Table S3). Basophil sensitivity to Pru $p$ 7-induced activation was monitored through $\mathrm{EC}_{50}, \mathrm{CD}$-sens and the lowest activating concentration. Median $\mathrm{EC}_{50}$ was $0.05 \mathrm{ng} / \mathrm{mL}$ (IQR 0.0125-1.25) and median CD-sens was 2000 (IQR 80-8000). EC 50 and the lowest activating concentration were lower in PA patients without cofactor involvement $(n=6)$ than in those who required a cofactor for reaction to peach $(n=3)$, with a similar trend for CDsens (Table 3). The ratio of maximal rPru $p$ 7-induced activation to anti-RFcel-induced activation was close to 1 in both groups.

\subsection{IgE to Pru p 7 is associated with and cross-reactive to IgE to cypress pollen}

We have previously described a ubiquitous co-sensitization to CP in Pru p 7 sensitized individuals. ${ }^{16}$ Among the 171 Pru p 7 sensitized subjects in the present study, all but one, who had Pru $p 7 \operatorname{lgE}$ at the positivity threshold of the assay $\left(0.10 \mathrm{kU}_{\mathrm{A}} / \mathrm{L}\right)$, were also sensitized to CP.

To study more directly a likely cross-reactivity between Pru $\mathrm{p} 7$ and $\mathrm{CP}$, we performed a dose-response IgE competition experiment with sera from four patients sensitized to $C P$ and Pru $p$ 7. Preincubation with different concentrations of $\mathrm{CP}$ extract caused a gradually increasing and ultimately almost complete (98-99\%) inhibition of IgE binding to Pru p 7 at the final inhibitor concentration of $15 \%(w / v)$ (not shown). In contrast, preincubation with Pru p 7 only partly (6772\%) prevented IgE binding to immobilized CP extract even at the highest inhibitor concentration applied (not shown).

We next performed single-point inhibition of IgE binding to Pru p 7 in 42 patients' sera, with a fixed final concentration of $15 \%(w / v)$ of $\mathrm{CP}$ extract. This resulted in $>80 \%$ inhibition in 38 of the 42 sera and $>60 \%$ in the remaining four (Figure $5 \mathrm{~A}$ ). Conversely, single-point

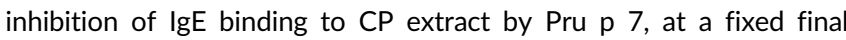
concentration of $100 \mu \mathrm{g} / \mathrm{mL}$, was performed in 33 patients' sera and resulted in $>40 \%$ inhibition in only $9 / 33(27 \%)$ and less than $20 \%$ in $10 / 33(30 \%)$ of the sera tested (Figure 5B). The ability of Pru $p 7$ to inhibit IgE binding to $\mathrm{CP}$ extract was negatively correlated to the ratio of IgE to Cup a 1/Pru p 7 (Spearman rho $-0.7, \mathrm{Cl} 95-0.9$ to
$-0.5, P<0.0001$ ), reflecting the proportion of CP-specific IgE directed to Cup a 1, which is structurally unrelated to Pru $\mathrm{p} 7$.

\subsection{Cypress pollen exposure determines regional peach molecular sensitization profiles}

Using a multivariate model of CP sensitization including all tested peach allergens as covariates, we found that no peach allergen other than Pru p 7 was significantly associated with CP sensitization (Table S4). The relationship between $\mathrm{CP}$ and Pru $\mathrm{p} 7$ sensitization was further assessed by sorting patients by region of residency as described in Methods (Table 1). Ordinal logistic regression models illustrated a strong relationship between the cypress/birch pollen count ratio and the occurrence of sensitization to $\mathrm{CP}$, Pru $\mathrm{p} 7$ or Pru p 1 (Table S5). This relationship was positive for CP and Pru p 7 sensitization $(P<0.0001$ and $P=0.0001$, respectively), and inverse for Pru $\mathrm{p} 1$ sensitization, a surrogate of Bet $v 1$ sensitization $(P=0.03)$. Further multivariate analysis of $\mathrm{CP}$, Pru $\mathrm{p} 1$ and Pru $\mathrm{p} 7$ sensitizations found independent relationships between these covariates and cypress/birch pollen count ratios, consisting of a quantitative effect of $\mathrm{CP}$ exposure associated with higher prevalence of Pru $p 7$ $(P=0.03)$ and lower prevalence of Pru p 1 sensitization $(P=0.003)$ among CP sensitized subjects (Table $\mathrm{S} 5$ ).

\section{4 | DISCUSSION}

We report here that Pru $\mathrm{p} 7$ is a major allergen in PA patients from southern France, in this study showing a prevalence of Pru $\mathrm{p} 7$ sensitization exceeding $60 \%$. In $54 \%$ of Pru p 7 -sensitized PA patients, there was no concomitant sensitization to other available peach allergens. The occurrence and level of Pru p 7 sensitization were higher in severe PA with peach-induced anaphylactic manifestations, that is grade 3 reactions of the EAACl classification, ${ }^{23}$ than in PA patients with lower grade reactions. The functional potency of Pru $p$ 7 was confirmed with BAT. Strong basophil activation was induced in Pru $\mathrm{p}$ 7-sensitized PA patients, with lowest activating concentrations of Pru $p 7$ in the range of picograms/millilitre and median $\mathrm{EC}_{50}$ at $0.05 \mathrm{ng} / \mathrm{L}$, while median CD-sens was 2000 , indicating a biological potency higher than other food allergens. ${ }^{33,35-37}$

In all but one borderline case in this study, Pru p 7 sensitization was associated with $\mathrm{CP}$ sensitization. The link between CP and Pru p 7 sensitization was further explored with IgE competition experiments. We found that CP extract could inhibit $80-100 \%$ of IgE binding to Pru $\mathrm{p} 7$ in $90 \%$ of the 42 sera analysed, whereas Pru p 7 only partly inhibited IgE binding to CP extract. Based on these results and the association between Pru $\mathrm{p} 7$ sensitization and the intensity of $\mathrm{CP}$ exposure, we believe that $\mathrm{CP}$ acts as a primary sensitizer, eliciting in a proportion of individuals an IgE response that cross-reacts with Pru $\mathrm{p}$ 7. A partially characterized $14 \mathrm{kDa}$ CP protein called BP14 has been shown to share a stretch of homology and cross-reactivity with snakin-1 from potato, a protein related to Pru p 7 and other members of the GRP protein family. ${ }^{38}$ In our study, clinical reactions to 
TABLE 2 Pru p 7 sensitization by geographic region and peach allergy or tolerance

\begin{tabular}{|c|c|c|c|c|c|c|}
\hline rPru p 7 lgE & All regions & Region 5 & Region 4 & Region 3 & Region 2 & Region 1 \\
\hline \multicolumn{7}{|l|}{ Peach allergic patients } \\
\hline Prevalence (number, \%) & $123(62 \%)^{* * *}$ & $88(66 \%)^{* *}$ & 12 (55\%) & $13(65 \%)^{* * *}$ & 7 (54\%) & $3(30 \%)$ \\
\hline Pru p 7 monosensitization & $66 / 123(54 \%)^{* * *}$ & $49 / 88(55 \%)^{* * *}$ & $7 / 12(58 \%)$ & $8 / 13(62 \%)$ & $1 / 7(14 \%)$ & $1 / 3(33 \%)$ \\
\hline \multicolumn{7}{|l|}{ Peach tolerant patients } \\
\hline Median (IQR) $\left(\mathrm{kU}_{\mathrm{A}} / \mathrm{L}\right)$ & $0.3(0.2-0.5)$ & $0.3(0.2-0.7)$ & $0.3(0.2-0.4)$ & $0.2(0.2 ; 0.2)$ & $0.1(0.1-0.2)$ & $0.2(0.2-0.4)$ \\
\hline Pru p 7 monosensitization & $8 / 48(17 \%)^{* * *}$ & $7 / 35(20 \%)^{* * *}$ & 0 & 0 & 0 & $1 / 3(33 \%)$ \\
\hline \multicolumn{7}{|l|}{ All patients } \\
\hline Prevalence (number, \%) & $171(54 \%)$ & $123(60 \%)$ & $16(59 \%)$ & 15 (43\%) & $11(39 \%)$ & $6(29 \%)$ \\
\hline Median (IQR) $\left(\mathrm{kU}_{\mathrm{A}} / \mathrm{L}\right)$ & $1.3(0.2-6.4)$ & $2.3(0.3-6.7)$ & $1.2(0.5-5.1)$ & $3.4(0.3-6.3)$ & $0.2(0.1-0.2)$ & $0.2(0.2-0.5)$ \\
\hline
\end{tabular}

Bold figures with asterisks denote statistically significant differences between PA and PT patients. Median and IQR were calculated for samples with Pru p 7 IgE $\geq 0.10 \mathrm{kU}_{\mathrm{A}} / \mathrm{L}$. Statistical significance flags for $P$-value levels: $*<0.05 ; * *<0.01 ; * * *<0.001$.

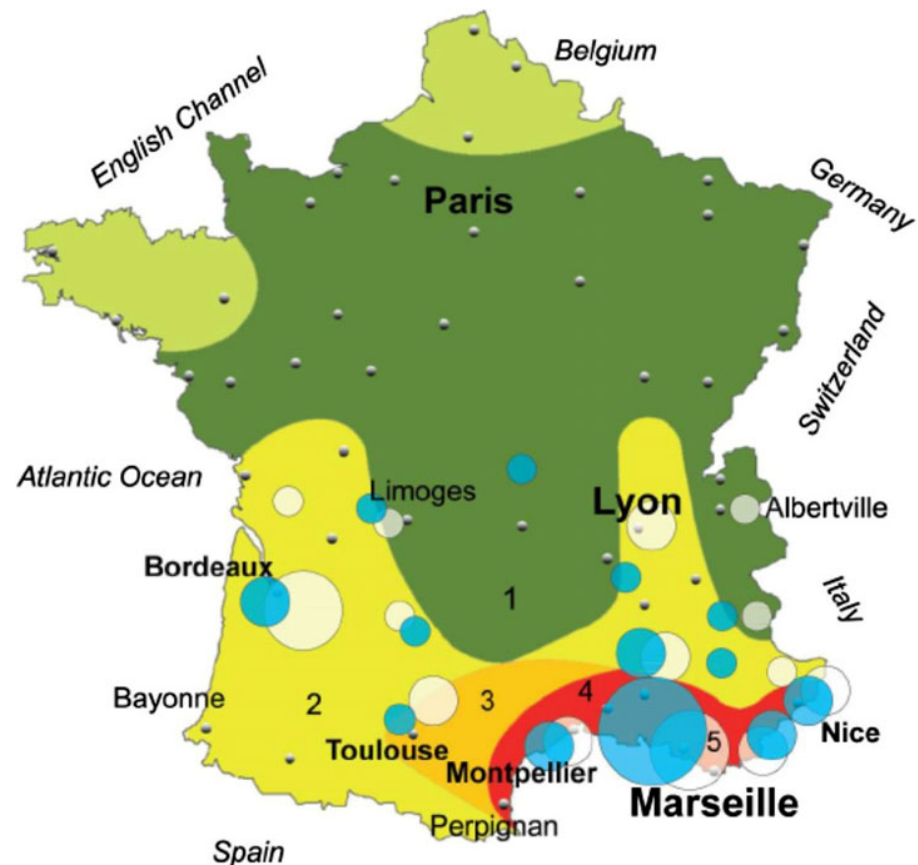

potato were reported by only two Pru p 7 sensitized patients, one of which was additionally sensitized to Pru $\mathrm{p} 4$.

Our data show that Pru p 7 sensitization in PA patients from southern France belongs to the PFS through its association with CP. Similar to other examples of PFS, Pru $\mathrm{p}$ 7-induced reactions occur mainly in adolescents and young adults. However, food allergy symptoms are more severe in Pru p 7-related PFS than in previously described examples of PFS.

Despite early reports on the association of PA with cypress pollinosis, ${ }^{39}$ the prevalence of cypress-associated peach sensitization and PA is currently unknown. In a cohort of 1280 cypress-sensitized patients from France, 165 (13\%) patients had peach sensitization as defined by positive prick-to-prick tests to peach, and 29 of these 165 (18\%) had a history of peach-induced symptoms. ${ }^{40}$ In regard to molecular sensitization relevant to peach allergy in our region,
Number of subjects

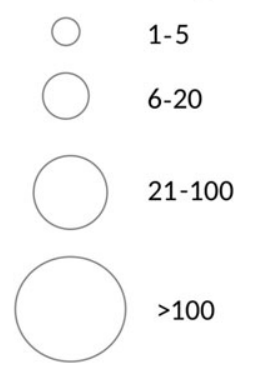

FIGURE 1 Prevalence of Pru $\mathrm{p} 7$ sensitization in southern France in relation to cypress pollen exposure levels. Cypress pollen levels: green, low (exposure region 1); yellow, intermediate (exposure region 2); orange, high (exposure region 3); red, very high (exposure regions 4 and 5). Birch pollen exposure follows an inverse gradient and is virtually absent in the southernmost part defining the region of Marseille (5). Pru p 7 sensitization: blue circles: sensitized subjects; white circles: nonsensitized subjects. The size of each circle indicates the number of subjects it represents. Small black and white symbols indicate sites of pollen counting. Cypress pollen map reproduced with permission ${ }^{17}$

preliminary data indicate that $15-25 \%$ of cypress pollinosis patients may be Pru $\mathrm{p} 7$ sensitized (unpublished observations). Peach IgE sensitization rates across European countries as reported from the Europrevall cohort peak at $11.9 \%$ in Madrid and $13.4 \%$ in Zurich. ${ }^{2}$

Similarly, little is known about allergen(s) other than Pru $\mathrm{p} 7$ potentially involved in the cypress-peach syndrome. ${ }^{41}$ Teams from southern France and Spain reported an association of CP and PA in Pru p 3 sensitized patients. ${ }^{42,43}$ Further, in a series of seven CP and PA patients, all displayed IgE binding to a $45-\mathrm{kDa} C P$ protein, which could be outcompeted by peach extract. ${ }^{39}$ Additionally, certain allergens identified in Japanese cedar (Cryptomeria japonica) pollen, such as Cry j 3 (thaumatin-like protein), CJP-6 (isoflavone-reductase) and CPA-9 (subtilisinlike protease), show sequence identity of $40 \%$ or higher with homologues in Rosaceae fruits and other plant foods, suggesting that crossreactions may occur through multiple allergen families. ${ }^{44}$ 

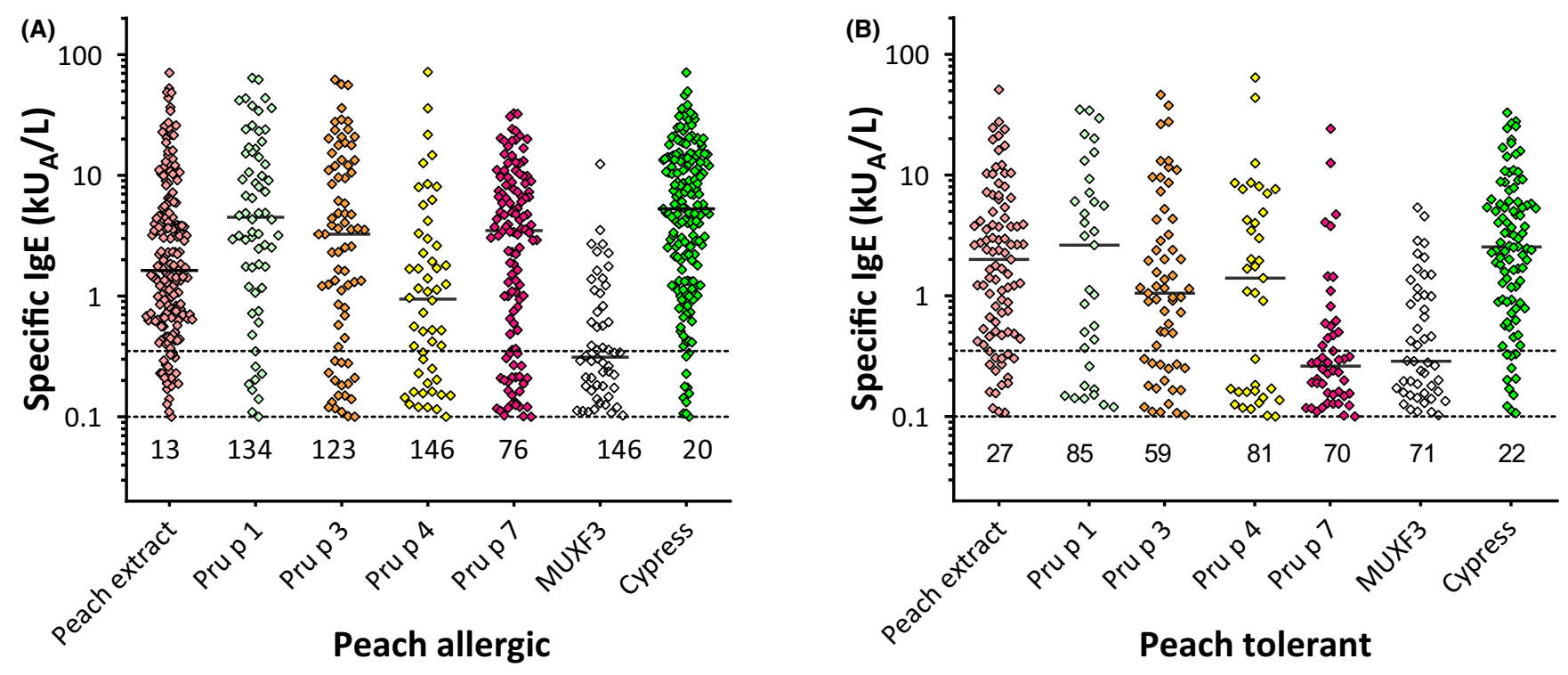

FIGURE 2 IgE antibody levels in peach allergic and peach tolerant patients. Levels of IgE to peach and peach components, MUXF3 and cypress pollen in peach allergic $(A)$ and peach tolerant $(B)$ subjects. Horizontal bars indicate median levels among positive $(\geq 0.10 \mathrm{kU} / \mathrm{L}$ ) observations. Dotted horizontal lines indicate the 0.10 and $0.35 \mathrm{kU}_{\mathrm{A}} / \mathrm{L}$ levels. Indicated above the $x$-axis in each graph are the numbers of sera with $\lg \mathrm{E}<0.10 \mathrm{kU}_{\mathrm{A}} / \mathrm{L}$
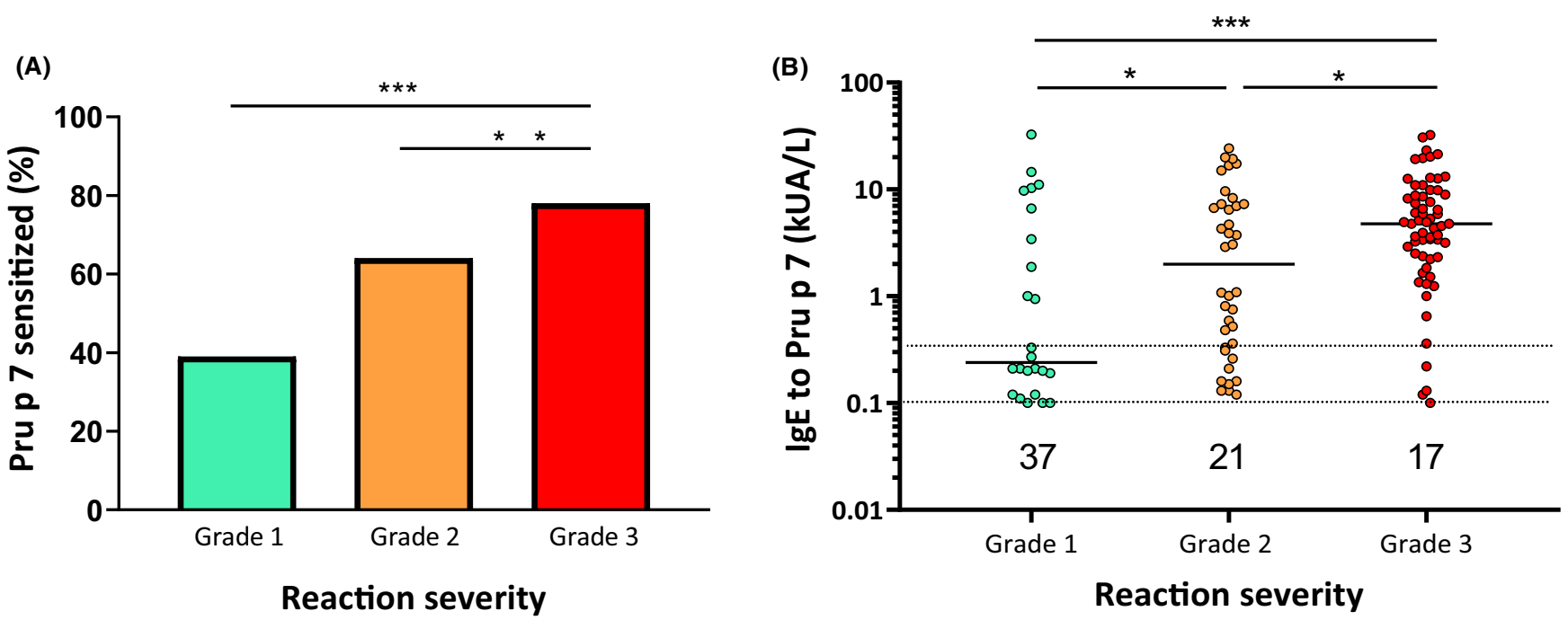

FIGURE 3 Prevalence and magnitude of Pru p 7 sensitization in relation to the severity of reactions to peach. Prevalence (A) and concentration (B) of IgE to Pru $\mathrm{p} 7$ in patients with mild, moderate or severe reactions to peach. Statistical significance flags for $P$-value levels: $*<0.05, * *<0.01, * * *<0.001$. In $\mathrm{B}$, horizontal bars indicate median levels among positive $\left(\geq 0.10 \mathrm{kU}_{\mathrm{A}} / \mathrm{L}\right)$ observations and dotted horizontal lines mark the 0.10 and $0.35 \mathrm{kU}_{\mathrm{A}} / \mathrm{L}$ levels. Indicated above the $x$-axis is the number of sera with $\operatorname{lgE}<0.10 \mathrm{kU}_{\mathrm{A}} / \mathrm{L}$

Although cypress trees are typical of Mediterranean regions, Cupressaceae pollen dispersal also affects non-Mediterranean environments, including Central Europe, North America, Mexico and Japan. ${ }^{41,45-48}$ GRP-related allergy to Rosaceae and Citrus fruits was reported in conjunction with Japanese cedar pollinosis. ${ }^{46,47,49}$ In south-central United States, mountain cedar (Juniperus ashei) pollen is a major cause of allergic rhinoconjunctivitis. ${ }^{48}$ Pollinosis to Cupressaceae has been steadily increasing during the past decades, possibly as a result of extended species distribution due to climate change and ability of Cupressaceae pollen to travel over hundreds of kilometres. ${ }^{41,44,48}$ Individuals with Cupressaceae pollinosis who display similar sensitization profiles due to the homology of allergens from different Cupressaceae species ${ }^{50}$ might become exposed to previously unencountered, cross-reacting foods, when changing residence regions, travelling overseas, or expanding their consumption of fruits and vegetables as a result of healthy living trends. ${ }^{51}$ Indeed, we found that Pru p 7 sensitization was associated with reactions to an array of plant foods, including but not limited to Rosaceae. Members of the GRP family are widely distributed in the plant kingdom, share high levels of sequence identity ${ }^{14,49,52}$ and have been 
(A)

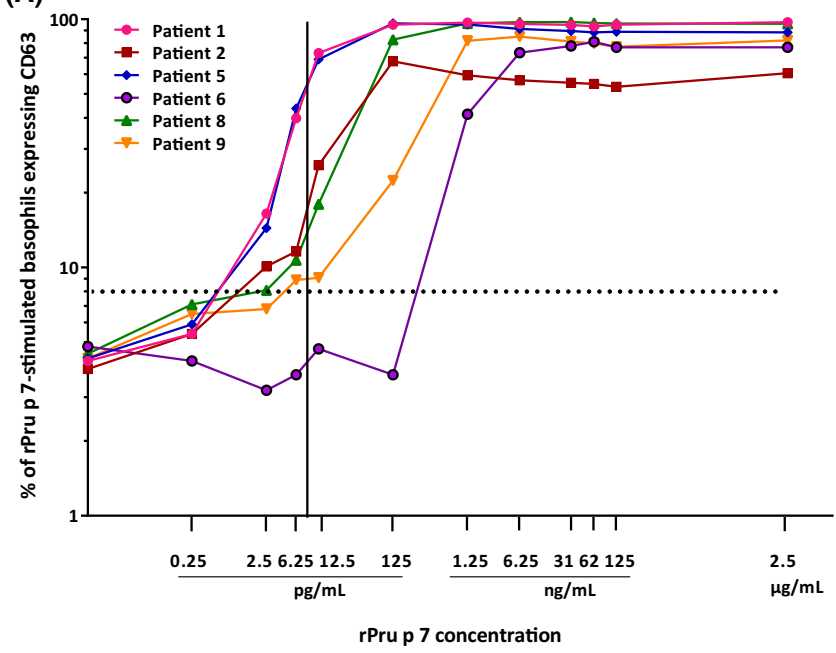

(B)

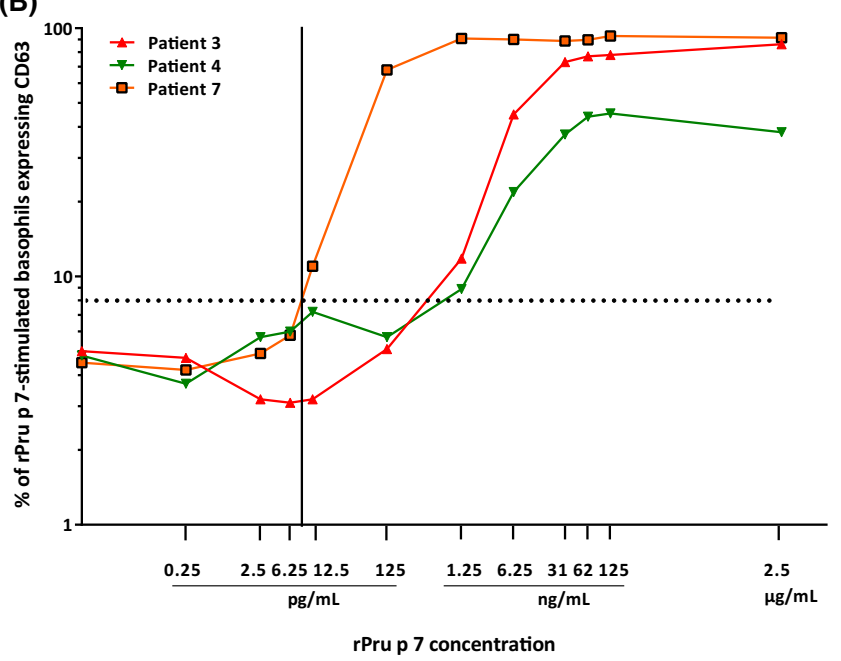

FIGURE 4 Dose-response of basophil activation with rPru $p$ 7. Dose-response BAT with rPru $p 7$ was performed in nine PA patients monosensitized to Pru $\mathrm{p}$ 7. A, BAT in individual PA patients without cofactor requirement. B, BAT in individual PA patients with clinical reactions requiring cofactors. The dotted line represents the positivity threshold. The solid line shows the separation between BAT with lowest activating concentrations below or greater than $6.25 \mathrm{pg} / \mathrm{mL}$ of $\mathrm{rPru} \mathrm{p} 7$

TABLE 3 Basophil activation test with rPru $\mathrm{p} 7$ in a sample of peach allergic patients

\begin{tabular}{|c|c|c|c|c|}
\hline & All & Without cofactor & With cofactor & $P$ \\
\hline Number of subjects & 9 & 6 & 3 & \\
\hline $\mathrm{EC}_{50} \mathrm{ng} / \mathrm{mL}$ (median, range) & $0.05(0.006-6.3)$ & $0.03(0.006-1.3)$ & $6.3(0.05-6.3)$ & 0.03 \\
\hline AUC & 9990 & 10579 & 8987 & 0.30 \\
\hline Lowest activating concentration $\mathrm{ng} / \mathrm{mL}$ (median, range) & $0.006(0.006-1.3)$ & $0.004(0.003-1.3)$ & $1.3(0.01-1.3)$ & 0.048 \\
\hline
\end{tabular}

Bold figure denotes statistically significant differences between peach allergic patients experiencing clinical reactions to peach without cofactor intervention and peach allergic patients requiring a cofactor.

associated with particularly severe food allergic reactions in at least three environments: Italy, ${ }^{14}$ France ${ }^{16}$ and Japan. ${ }^{49,53}$

In our cohort, increasing CP exposure and associated Pru $\mathrm{p} 7$ sensitization was related to lower prevalence of PR-10 sensitization even in regions with substantial birch pollen exposure. Conversely, a potential protective effect of birch pollen exposure has been suggested with respect to LTP-related food allergies. ${ }^{54}$ The pathophysiological background of such interactions between pollen exposure and the resulting host sensitization may bring further insight into the geographic restriction patterns of food allergy.

In conclusion, we report here that Pru p 7 sensitization is common in patients allergic to peach, often in the absence of sensitization to other peach allergens. Sensitization to Pru $\mathrm{p} 7$ is invariably associated with $\mathrm{CP}$ sensitization and appears to be driven by $\mathrm{CP}$ exposure, rather than reflecting a primary food sensitization. Biologically, Pru $\mathrm{p} 7$ was found to be extremely potent, causing basophil activation at sub-picomolar concentrations. Because $\mathrm{CP}$ is present in continental as well as Mediterranean environments, and given the world-wide distribution of related Cupressaceae species, Pru $\mathrm{p} 7$ and homologous food proteins may be an important culprit in severe allergic reactions to peach and other plant foods in many regions of the world.

\section{ACKNOWLEDGEMENTS}

The authors thank Mr Gérard Kiyici, Ms Isabelle Cleach, Ms Céline Chartier, Ms Patricia Blanchard, Mr Simon Pinchemel, Ms Colette Mavier for technical assistance; Dr Jean-Luc Fauquert and Dr Michel Migueres for insightful advice.

\section{CONFLICT OF INTEREST}

$A E E, J O ̈$ and $J L$ are employees of Thermo Fisher Scientific. RAL is employee of Beckman Coulter. PD has received speaker and consultancy fees from ALK, Circassia, Stallergènes Greer, Allergopharma, Thermo Fisher Scientific, Meda, Menarini and grants from AstraZeneca and from MEDA Pharma through CHRUM administration. LGC has received reimbursement for attending a symposium and a fee for organizing education from Thermo Fisher Scientific. PAA has received reimbursement for attending a congress from Thermo Fisher Scientific and a research grant from the French Society of Allergology. YPMB has received speaker fees from Thermo Fisher Scientific, ALK-Abello, Stallergènes. IAM has received research grants from the European Union. JV has received speaker and consultancy fees from Meda 
(A)

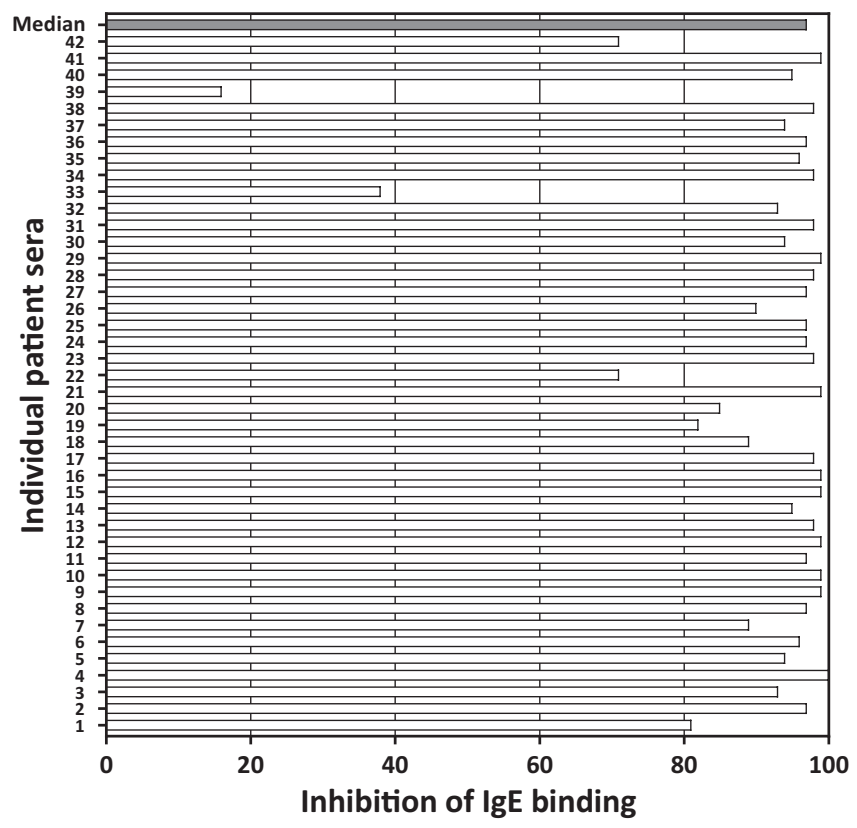

(B)

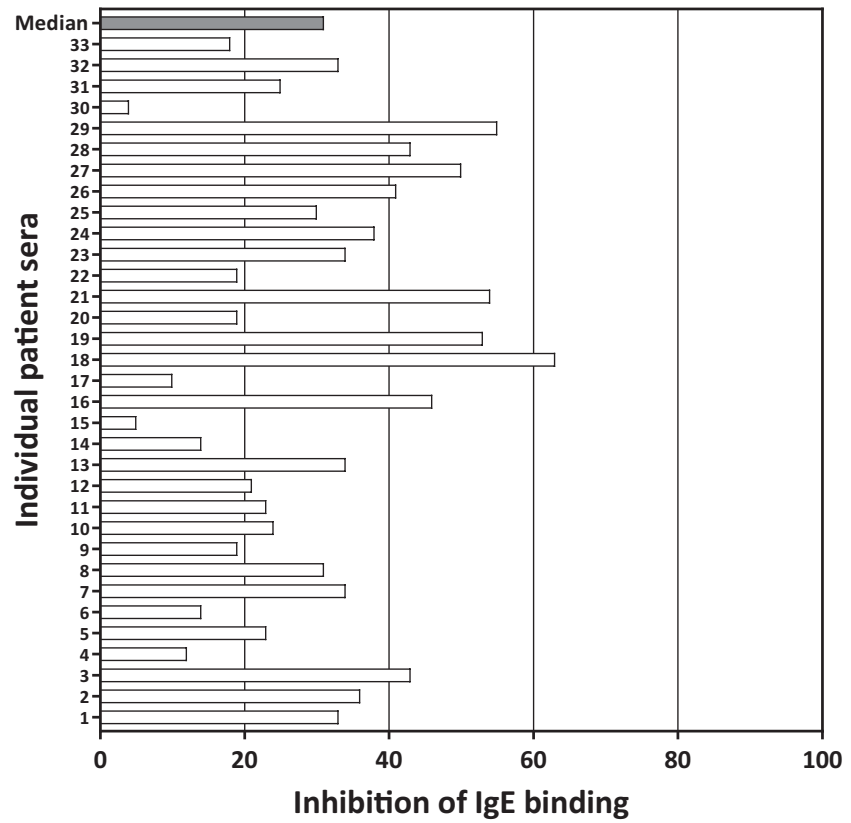

FIGURE 5 Reciprocal IgE inhibition experiments. Sera of peach allergic subjects were pre-incubated with either (A) cypress pollen extract (15\% $\mathrm{w} / \mathrm{v}, \mathrm{n}=42)$ or $(\mathrm{B}) \mathrm{rPru}$ p $7(100 \mu \mathrm{g} / \mathrm{mL}, \mathrm{n}=33)$ prior to measurement of IgE binding to rPru $\mathrm{p} 7$ or cypress pollen abstract, respectively, by ImmunoCAP ${ }^{\mathrm{TM}}$. Resulting degrees of inhibition are expressed as percent reduction of IgE concentration values as compared to measurements performed after preincubation with buffer alone, without inhibitor. Median inhibition is represented as a grey bar at the upper end of each graph

Pharma, Mylan, Sanofi, reimbursement for attending a congress from Thermo Fisher Scientific and research grants from the French Society of Allergology. The other authors declare no conflict of interest.

\section{AUTHOR CONTRIBUTIONS}

$\mathrm{CK}$, JL and JV conceived, designed and supervised the study. CK, AS, PAA, MV, LG, CS, SM and JV supervised laboratory procedures and collected and analysed clinical and laboratory data. YC and JV performed statistical analysis. RAL and JV performed BAT experiments. AEE and JÖ produced natural and recombinant Pru $\mathrm{p} 7$ and Pru p 3, performed experimental ImmunoCAP IgE measurements and IgE inhibition tests. AP, VL, CA, JB, FP, AMC, DPC, JLB, PD, SG, FB, BL, CP, SL, TB, LGC, MG, AAD, DC, TS, ICB, YPM, BH, NB, MDG, $\mathrm{BS}, \mathrm{AC}, \mathrm{SV}, \mathrm{BP}, \mathrm{LN}, \mathrm{GL}, \mathrm{SM}$ performed clinical allergy work-up and collected and analysed clinical data. CK, YC, AEE, AS, AMC, JLB, DC, $B S$, JL and JV wrote the paper. IAM and JLM revised the paper for important intellectual content. All authors read and approved the final manuscript.

\section{REFERENCES}

1. Asero R, Antonicelli L, Arena A, et al. EpidemAAITO: features of food allergy in Italian adults attending allergy clinics: a multi-centre study. Clin Exp Allergy. 2009;39:547-555.

2. Burney PG, Potts J, Kummeling I, et al. The prevalence and distribution of food sensitization in European adults. Allergy. 2014;69:365-371.

3. Fernández-Rivas M. Fruit and vegetable allergy. Chem Immunol Allergy. 2015;101:162-170.
4. Sánchez-López J, Gázquez V, Rubira N, et al. Food allergy in Catalonia: clinical manifestations and its association with airborne allergens. Allergol Immunopathol. 2017;45:48-54.

5. Grabenhenrich LB, Dölle S, Moneret-Vautrin A, et al. Anaphylaxis in children and adolescents: the European Anaphylaxis Registry. J Allergy Clin Immunol. 2016;137:1128-1137.

6. Alvarez-Perea A, Ameiro B, Morales C, et al. Anaphylaxis in the pediatric emergency department: analysis of 133 cases after an allergy workup. J Allergy Clin Immunol Pract. 2017;5:1256-1263.

7. Cuesta-Herranz J, Lazaro M, Martinez A, et al. Pollen allergy in peach-allergic patients: sensitisation and cross-reactivity to taxonomically unrelated pollens. J Allergy Clin Immunol 1999;104:688-694.

8. Ma S, Sicherer SH, Nowak-Wegrzyn A. A survey on the management of pollen-food allergy syndrome in allergy practices. J Allergy Clin Immunol. 2003;112:784-788.

9. Andersen MB, Hall S, Dragsted LO. Identification of European allergy patterns to the allergen families PR-10, LTP, and profilin from Rosaceae fruits. Clin Rev Allergy Immunol. 2011;41:4-19.

10. Mastrorilli C, Tripodi S, Caffarelli C, et al. Endotypes of pollen-food syndrome in children with seasonal allergic rhinoconjunctivitis: a molecular classification. Allergy. 2016;71:1181-1191.

11. Gamboa PM, Caceres O, Antepara I, et al. Two different profiles of peach allergy in the north of Spain. Allergy. 2007;62:408-414.

12. Asero R, Piantanida M, Pinter E, Pravettoni V. The clinical relevance of lipid transfer protein. Clin Exp Allergy. 2018;48:6-12.

13. Flores E, Cervera L, Sanz ML, Diaz-Perales A, Fernández J. Plant food allergy in patients with pollinosis from the Mediterranean area. Int Arch Allergy Immunol. 2012;159:346-354.

14. Tuppo L, Alessandri C, Pomponi D, et al. Peamaclein - A new peach allergenic protein: similarities, differences and misleading features compared to Pru p 3. Clin Exp Allergy. 2013;43:128-140.

15. Tenenbaum J, Leoni MC, Demoly MP, Bourrain JL, Demoly P, Chiriac AM. Allergie à la pêche avec taux d'IgE spécifiques pêche et allergènes majeurs négatifs ou faiblement positifs. Rev Fr Allergol. 2016;56:441445. 
16. Klingebiel C, Poisson A, Lidholm J, et al. Peamacléine Pru p 7: épidémiologie, implications cliniques et place dans le diagnostic moléculaire de l'allergie à la pêche en région méditerranéenne. Rev Fr Allergol. 2018;58:16-22.

17. Le Réseau National de Surveillance Aérobiologique (R.N.S.A.), http:// www.pollens.fr/accueil.php, accessed on Dec 5th, 2017.

18. Burks AW, Tang M, Sicherer S, et al. ICON: food allergy. J Allergy Clin Immunol. 2012;129:906-920.

19. Muraro A, Werfel T, Hoffmann-Sommergruber K, et al. EAACl food allergy and anaphylaxis guidelines: diagnosis and management of food allergy. Allergy. 2014;69:1008-1025.

20. Werfel T, Asero R, Ballmer-Weber BK, et al. Position paper of the EAACl: food allergy due to immunological cross-reactions with common inhalant allergens. Allergy. 2015;70:1079-1090.

21. Muraro A, Lemanske RF Jr, Castells $M$, et al. Precision medicine in allergic disease-food allergy, drug allergy, and anaphylaxis-PRACTALL document of the European Academy of Allergy and Clinical Immunology and the American Academy of Allergy, Asthma and Immunology. Allergy. 2017;72:1006-1021.

22. Niggemann B, Beyer K. Time for a new grading system for allergic reactions. Allergy. 2016;71:135-136.

23. Muraro A, Fernandez-Rivas M, Beyer K, et al. The urgent need for a harmonized severity scoring system for acute allergic reactions. Allergy. 2018;73:1792-1800

24. Loi no. 2012-300 du 5 mars 2012. Journal Officiel de la République Française 2012; March 5.

25. Décret no. 2016-1537 du 16 novembre 2016. Journal Officiel de la République Française 2016; Nov 16.

26. Kleine-Tebbe J, Jakob T. Molecular allergy diagnostics in clinical pratice, pp 16-24. In: Matricardi PM, Kleine-Tebbe J, Hoffmann HJ, Valenta R, Hilger C, Hofmaier S, et al. EAACl Molecular Allergology User's Guide, Pediatr Allergy Immunol. 2016;27(Suppl. 23):1-250.

27. Tordesillas L, Gómez-Casado C, Garrido-Arandia M, et al. Transport of Pru p 3 across gastrointestinal epithelium - an essential step towards the induction of food allergy? Clin Exp Allergy. 2013;43:1374-1383.

28. Lambert C, Sarrat A, Bienvenu F, et al. The importance of EN ISO 15189 accreditation of allergen-specific IgE determination for reliable in vitro allergy diagnosis. Allergy. 2015;70:180-186.

29. Alessandri C, Ferrara R, Bernardi ML, et al. Diagnosing allergic sensitisations in the third millennium: why clinicians should know allergen molecule structures. Clin Transl Allergy. 2017;7:21.

30. Tuppo L, Giangrieco I, Alessandri C, et al. Pomegranate chitinase III: Identification of a new allergen and analysis of sensitization patterns to chitinases. Mol Immunol. 2018;103:89-95.

31. Marknell DeWitt $\AA$, Niederberger V, Lehtonen P, et al. Molecular and immunological characterization of a novel timothy grass (Phleum pratense) pollen allergen, Phl p 11. Clin Exp Allergy. 2002;32:1329-1340.

32. Johansson SG, Nopp A, van Hage M, et al. Passive IgE-sensitization by blood transfusion. Allergy. 2005;60:1192-1199.

33. Santos AF, Du Toit G, Douiri A, et al. Distinct parameters of the basophil activation test reflect the severity and threshold of allergic reactions to peanut. J Allergy Clin Immunol. 2015;135:179-186.

34. Bland JM, Altman DG. Statistics notes. The odds ratio. BMJ. 2000; 320:1468.

35. Schwager C, Kull S, Behrends J, et al. Peanut oleosins associated with severe peanut allergy-importance of lipophilic allergens for comprehensive allergy diagnostics. J Allergy Clin Immunol. 2017;140:1331-1338.

36. Franz-Oberdorf $\mathrm{K}$, Eberlein $\mathrm{B}$, Edelmann $\mathrm{K}$, et al. Fra a 1.02 is the most potent isoform of the Bet $\vee$ 1-like allergen in strawberry fruit. J Agric Food Chem. 2016;64:3688-3696.

37. Martin-Pedraza L, Gonzalez M, Gomez F, et al. Two nonspecific lipid transfer proteins (nsLTPs) from tomato seeds are associated to severe symptoms of tomato-allergic patients. Mol Nutr Food Res. 2016;60:1172-1182.
38. Senechal H, Santrucek J, Melcova $M$, et al. A new allergen family involved in pollen food-associated syndrome: Snakin/gibberellin-regulated proteins. J Allergy Clin Immunol. 2018;141:411-414.

39. Hugues B, Didierlaurent A, Charpin D. Cross-reactivity between cypress pollen and peach: a report of seven cases. Allergy. 2006;61:1241-1243.

40. Caimmi D, Raschetti R, Pons P, et al. Epidemiology of cypress pollen allergy in Montpellier. J Investig Allergy Clin Immunol. 2012;22:280-285.

41. Charpin D, Pichot C, Belmonte J, et al. Cypress pollinosis: from tree to clinic. Clin Rev Allergy Immunol. 2017; https://doi.org/10.1007/ s12016-017-8602-y.

42. Caimmi D, Barber D, Hoffmann-Sommergruber K, et al. Understanding the molecular sensitisation for cypress pollen and peach in the Languedoc-Roussillon area. Allergy. 2013;68:249-251.

43. Sánchez-López J, Asturias JA, Enrique E, Suárez-Cervera M, Bartra J. Cupressus arizonica pollen: a new pollen involved in the lipid transfer protein syndrome? J Investig Allergol Clin Immunol. 2011;21:522-526.

44. Fujimura T, Kawamoto S. Spectrum of allergens for Japanese cedar pollinosis and impact of component-resolved diagnosis on allergenspecific immunotherapy. Allergol Int. 2015;64:312-320.

45. Panzner P, Vachova M, Vitovcova P, Brodska P, Vlas T. A comprehensive analysis of middle-European molecular sensitisation profiles to pollen allergens. Int Arch Allergy Immunol. 2014;164:74-82.

46. Inomata N, Miyakawa M, Aihara M. High prevalence of sensitisation to gibberellin-regulated protein (peamaclein) in fruit allergies with negative immunoglobulin $E$ reactivity to Bet $v 1$ homologs and profilin: clinical pattern, causative fruits and cofactor effect of gibberellin-regulated protein allergy. J Dermatol. 2017;44:735-741.

47. Inomata N, Miyakawa M, Aihara M. Gibberellin-regulated protein in Japanese apricot is an allergen cross-reactive to Pru p 7. Immun Inflamm Dis. 2017;5:469-479.

48. Mohanty RP, Buchheim MA, Anderson J, Levetin E. Molecular analysis confirms the long-distance transport of Juniperus ashei pollen. PLoS ONE. 2017;12:e0173465.

49. Inomata N, Miyakawa M, Ikeda N, Oda K, Aihara M. Identification of gibberellin-regulated protein as a new allergen in orange allergy. Clin Exp Allergy. 2018;48:1509-1520.

50. Pichler U, Hauser $M$, Wolf $M$, et al. Pectate lyase pollen allergens: sensitisation profiles and cross-reactivity pattern. PLOS ONE. 2014;44:438-449.

51. Skypala IJ. When nutrition and allergy collide: the rise of anaphylaxis to plant foods. Curr Opin All Im. 2017;17:338-343.

52. Nahirnak V, Almasia NI, Hopp HE, Vazquez-Rovere C. Snakin/GASA proteins: involvement in hormone crosstalk and redox homeostasis. Plant Signal Behav. 2012;7:1004-1008.

53. Inomata N, Okazaki F, Moriyama $\mathrm{T}$, et al. Identification of peamaclein as a marker allergen related to systemic reactions in peach allergy. Ann Allergy Asthma Immunol. 2014;112:175-177.

54. Rial MJ, Sastre J. Food allergies caused by allergenic lipid transfer proteins: what is behind the geographic restriction? Curr Allergy Asthma Rep. 2018;18:56. 